\title{
Fiziologija rasplođivanja kamelida - Anatomija spolnih organa i spolna zrelost I. dio
}

\author{
Dražen Đuričič, Iva Kilvain i Marko Samardžija
}

\section{Sažetak}

U prirodnim uvjetima rasplodna učinkovitost kamelida je relativno niska, a fiziologija rasplodnje se razlikuje u usporedbi s drugim domaćim životinjama. Generacijski interval je relativno dug, jer mužjaci kasno spolno sazrijevaju, a ženke imaju produženu gestaciju u odnosu na ostale domaće preživače. Kamelidi su sezonski poliestrične životinje čija je sezona pod utjecajem raznih čimbenika. Tijekom rasplodne sezone primjećuje se stalan razvoj funkcionalnih folikularnih valova. Ženke imaju induciranu ovulaciju, a ovulacija se inducira parenjem. Jednogrbe deve se smatraju spolno zrelima u dobi od dvije godine, ali su rasplodno zrele u dobi s 3 - 4, a mužjaci u dobi od 4 - 5 godina. Alpake dosegnu spolnu zrelost $u$ dobi od 12 - 14 mjeseci te se mogu pripustiti nakon 18 mjeseci, a mužjaci nakon 2 godine. Spolni ciklus u kamelida traje 2 - 3 tjedna, a estrus od 3 do 4 dana. Tijekom estrusa ženka je sposobna za pripust, odnosno umjetno osjemenjivanje, što pokazuje karakterističnim promjenama u ponašanju i izgledu vanjskih spolnih organa. Parenje se odvija u sjedećem stavu. Svaki ejakulat kamelida je malog volumena, ali velike viskoznosti i sadrži nisku koncentraciju spermija.

Ključne riječi: kamelidi, spolna zrelost, rasplodna zrelost, spolni ciklus

\section{Uvod}

Porodicu deva Camelidae (Gray, 1821.) čine sisavci koje svrstavamo $\mathrm{u}$ red parnoprstaša (Artiodactyla) i jedini podred Tylopoda (grč. tylo je žulj, grč. podi znači stopalo), a obitavaju u pustinjskim predjelima ili na visoravnima Anda. Iako nisu preživači kamelidi su poligastrične životinje i preživaju. Složeni želudac kamelida (Pérez i sur., 2016.) ima samo

tri različita odjeljka ili komore (C-1, C-2 i C-3) u odnosu na složeni želudac preživača koji se sastoji od četiri dijela. Porodicu Camelidae možemo podijeliti u dvije osnovne skupine: deve Starog i deve Novog svijeta. Deve Starog svijeta su prave deve koje posjeduju grbu(e), a čine ih dvije vrste: jednogrba deva ili dromedar (C. dromedarius) i dvogrba (Slika 1.) ili

Dr. sc. Dražen ĐURIČIĆ* ${ }^{*}$ dr. med vet., docent, (dopisni autor, e-mail: djuricic@vet.hr), Veterinarska stanica Đurđevac, Hrvatska, Iva KILVAIN, dr. med. vet., Hrvatski veterinarski institut, Veterinarski zavod Rijeka, Hrvatska; dr. sc. Marko SAMARDŽIJA, dr. med. vet., redoviti profesor, Veterinarski fakultet, Sveučilišta u Zagrebu, Hrvatska 
baktrijska deva (C. bactrianus). U deve Novog svijeta ili južnoameričke kamelide (Wheeler, 2012.), spadaju dvije domaće: ljama (Lama glama) i alpaka (Vicugna pacos) te dvije divlje vrste: gvanako (Lama guanicoe) i vikunja (Vicugna vicugna). Smatra se da je $40 \%$ ljama (Slika 2.) i $80 \%$ alpaka hibridizirano. Cilj je ovog rada bolje upoznati reprodukciju kamelida. Unatoč tome što ova porodica nije toliko zastupljena i gospodarski značajna $u$ Hrvatskoj, u nas, osim što predstavlja atrakciju, sve je veći trend uzgoja ovih životinja kao kućnih ljubimaca.

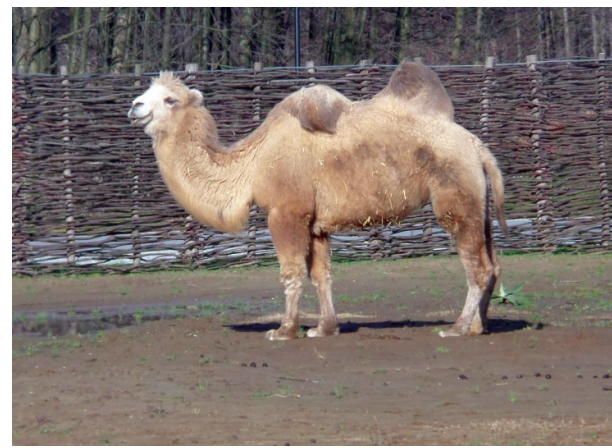

Slika 1. Dvogrba deva

\section{Anatomija ženskih spolnih organa}

Vanjski spolni organi sastoje se od ženskog kopulacijskog organa kojeg čine rodnica (vagina) s predvorjem (vestibulum vaginae) i stidnica (vulva). U unutarnje spolne organe ubrajamo: parne jajnike (ovarium), dva jajovoda (tuba uterina) i dvorožnu maternicu (uterus bicornis) s materničnim grljkom (cervix uteri).

Izgled i veličina jajnika kamelida varira ovisno o dobi i spolnoj aktivnosti. U predpubertetskih životinja jajnici imaju glatku i sjajnu površinu, a tijekom sezone parenja jajnici su neravni zbog prisutnosti dominantnih folikula i žutih tijela (corpora lutea (CL)) na njima. Zreli (dominantni) folikuli su pred ovulaciju promjera 13-20 $\mathrm{mm}$. Veliki anovulatorni folikuli (25$60 \mathrm{~mm}$ ) su prisutni u oko $50 \%$ ženki koje se nisu parile. Ovulacija se očituje pucanjem dominantnog ili Graafovog folikula te izbacivanjem jajne stanice u jajovod. Kad deva nije gravidna, CL je promjera 12-15 mm i mase oko 1,5-2 $\mathrm{g}$, a gravidna u prosjeku je veličine od 22 - 28 mm i 4,9 - 6 g mase. U slučaju da ne dođe do koncepcije dolazi do regresije CL 10-12 dana od neuspješnog parenja. U gravidnih se deva regresija CL javlja neposredno pred porođaj (Đuričić, 2018.). Jajnici u ljama i alpaka su parni elipsoidni do okrugli, a u mladih jedinki su zbog brojnih malih folikula bočno spljošteni i neravne površine (Vaughan

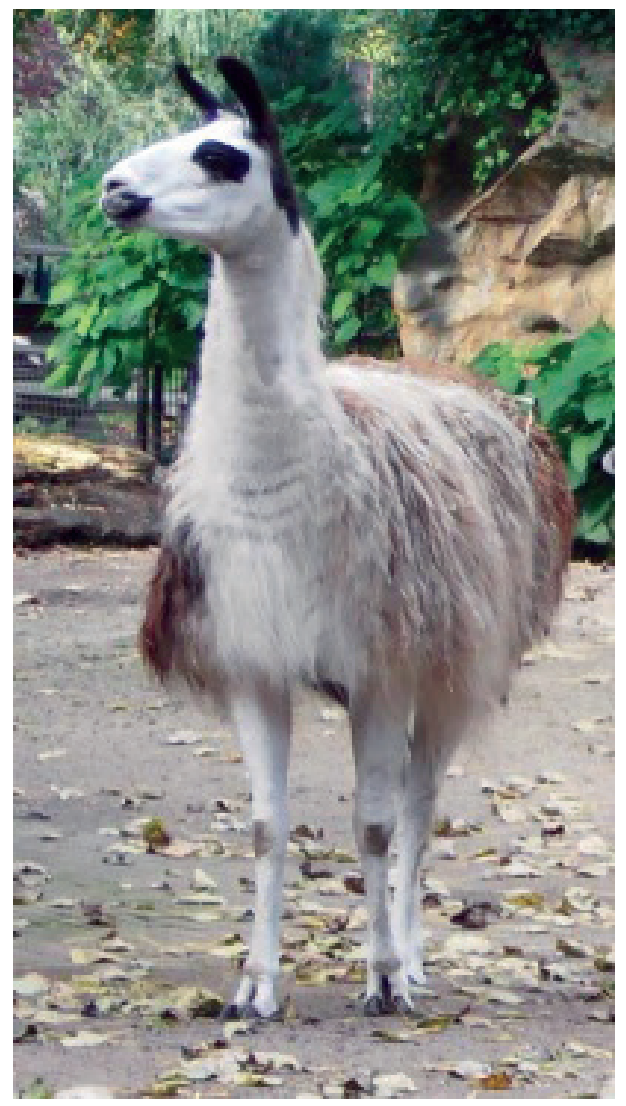

Slika 2. Ljama 
i Tibary, 2006.). Jajovod (tuba uterina) je u deva uska vijugava parna cjevčica na slobodnom kraju ljevkasto proširena poput cvijeta. Jajovod se otvara u rog maternice preko uskog otvora na vrhu gdje se nalazi uzdignuta papila za koju se pretpostavlja da je važna u prijenosu i odabiru oplođenih zametaka (Đuričić, 2017.). Maternica (uterus) je organ u kojemu se oplođena jajna stanica razvija i ostaje u njoj tijekom gravidnosti sve do porođaja. Sastoji se od grljka (cervix uteri), tijela (corpus uteri) i rogova (cornua uteri). Grljak maternice ima 3 - 4 kružna nabora sluznice. Maternica ima dva roga (uterus bicornis) od kojih je lijevi duži. Rogovi se razilaze i postaju šiljasti prema vrhu oblikujući slovo $\mathrm{T} u$ mladih ili Y u odraslih deva. Negravidna maternica ima kratko tijelo (Đuričić, 2018.). Rodnica (vagina) je cjevasti šuplji organ koji se nastavlja kaudalno na maternicu i cerviks. Smještena je ventralno ispod rektuma, a dorzalno iznad mokraćnog mjehura, uretre, preponske i sjedne kosti. Rodnicu od predvorja dijeli djevičanska opna (hymen femininus) i prsten čvrstog tkiva (m. constrictor vestibuli) (Đuričić, 2017.).

\section{Anatomija muških spolnih}

\section{organa}

Muške rasplodne organe (Slika 3.) čine puzdra (praeputium), kopulatorni organ (penis), muške sjemenske žlijezde ili testisi (testis, orchis), smješteni u mošnji (scrotum), nuzjaje (epididymis), sjemenovod (ductus deferens), mokraćnica (urethra masculina) te akcesorne spolne žlijezde: prostata (glandula prostatica) i bulbouretralne žlijezde (glandulae bulbourethrales).

Prepucij ili puzdra je dvostruka kožna prevlaka trokutastog oblika smještena $u$ sredini ingvinalnog područja koja prekriva penis i štiti ga od izravnih ozljeda. Mišići kod erekcije penisa usmjeravaju prepucij naprijed i natrag kod uriniranja, tako da mokraća prolazi natrag prema stražnjim nogama. U mužjaka alpake je kod rođenja prepucij prirastao s penisom, a priraslice postupno do rasplodne zrelosti nestaju (Fowler i Bravo, 1998.). Penis je muški kopulatorni organ fibroelastične građe koji se ispred mošnje savija, tj. ima sigmoidnu fleksuru. U deva Starog svijeta penis je dug $59-68 \mathrm{~cm}$, dok je u alpaka tijekom erekcije dužine $35-40 \mathrm{~cm}$,

Tabela 1. Veličine nekih ženskih spolnih organa kamelida

\begin{tabular}{|c|c|c|c|c|c|}
\hline ORGAN & POKAZATELJ & MJERA & DEVA & LJAMA & ALPAKA \\
\hline \multirow{3}{*}{ Jajnik } & dužina & \multirow{3}{*}{$\mathrm{cm}$} & $2,6-6,0$ & $1,3-2,5$ & $1,3-1,9$ \\
\hline & širina & & $2,0-4,0$ & $1,4-2,5$ & $0,9-1,3$ \\
\hline & visina & & n.p. & $0,5-1,0$ & $0,9-1,3$ \\
\hline Jajovod & dužina & $\mathrm{cm}$ & $17-28$ & $16,2-24,6$ & $10,5-18$ \\
\hline \multirow{3}{*}{ Maternica } & tijelo & \multirow{3}{*}{$\mathrm{cm}$} & $2,0-3,5$ & $3,0-5,5$ & $3,0-5,0$ \\
\hline & rogovi & & $8,0-15,0$ & $20,0-22,5$ & n.p. \\
\hline & grljak & & $5,0-6,0$ & $2,0-5,0$ & $2,0-5,0$ \\
\hline \multirow{2}{*}{ Rodnica } & dužina & \multirow[b]{2}{*}{$\mathrm{cm}$} & $25-30$ & $15-25$ & $11,4-15,4$ \\
\hline & promjer & & 6,0 & 5,0 & $2,7-4,1$ \\
\hline
\end{tabular}


a 36 - 45 cm u mužjaka ljame. Mokraćnica ili uretra (urethra) prolazi kroz utor tijela penisa. Glavić penisa (glans penis) dužine je 8 - $12 \mathrm{~cm}$ i pri vrhu oblikuje zaokruženi hrskavični izdanak (processus urethralis) koji tijekom parenja usmjerava penis kroz cerviks. Processus urethralis je u mužjaka pravih deva usmjeren lijevo i dorzalno, tako da oblikuje slovo T, a u alpake je zakrivljen u smjeru kazaljke na satu (Fowler i Bravo, 1998., Đuričić, 2017., Đuričić i sur., 2018.). Muške sjemenske žlijezde ili testisi su jajolikog oblika i slobodno pokretni u mošnji koji se nalaze $\mathrm{u}$ području međice (regio perinealis). U kamelida testisi ne vise, već prianjaju uz tijelo (kao u nerasta). Do spuštanja testisa (descensus testis) dolazi odmah po rođenju (Bravo i sur., 1994.). Na glavu pasjemenika koja leži kranioventralno uz testis se nastavlja tijelo koje se usmjerava medijalno i dorzokaudalno prema repu koji leži na dorzalnoj strani testisa. U glavi i tijelu pasjemenika odvija se sazrijevanje spermija, a rep služi kao skladište spermija. Pasjemenik je građen od niza kanalića složenih u zavoje koji čine režnjiće, a spajaju se u cijev (ductus epididymidis) koja utječe u sjemenovod (ductus deferens) dužine oko $40 \mathrm{~cm}$ (Đuričić, 2018.). Akcesorne spolne žlijezde su prostata i bulbouretralne žlijezde, dok vezikularne žlijezde (glandulae vesiculares) nisu razvijene. Prostata se nalazi iznad zdjeličnog dijela uretre i oblika je slova $\mathrm{H}$. U mužjaka deve je veličine $3-7 \times 5 \mathrm{~cm}$, a $3-4 \times 2 \mathrm{~cm}$ u ljama. Bulbouretralne žlijezde su parne žlijezde bademastog oblika smještene na području ishijadičnog luka s obje strane zdjeličnog dijela uretre pri korijenu penisa (Perk, 1962.), a izlučuju viskoznu tekućinu koja tvori ejakulat (Ali i sur., 1976.). Mužjak deve u okcipitalnoj regiji ima dvije zatiljne žlijezde (glandulae occipitales) koje tijekom rasplodne sezone izlučuju obilan tamno-smeđi sekret, intenzivnog i specifičnog mirisa (Tingari i George, 1984., Taha i sur., 1994.) koji ima

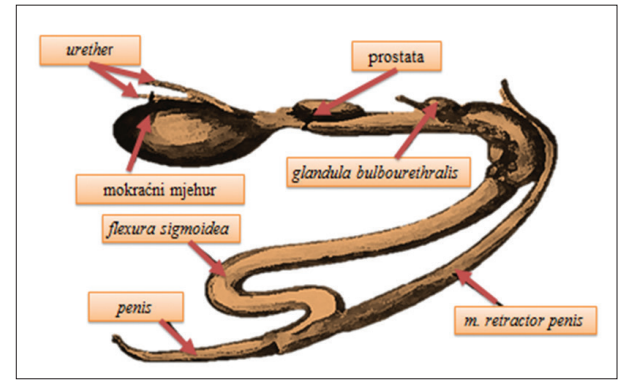

Slika 3. Muški spolni organi deva

ulogu označavanja teritorija i privlačenja ženke (Sumar, 1983., El-Wishy, 1988., Johnson, 1989., Bravo i sur., 1994., Smith, 1999.).

\section{Spolna zrelost}

Tijekom životnog vijeka sisavaca razlikuju se tri razdoblja povezana sa sposobnošću rasplodnje: predreprodukcijsko, reprodukcijsko i postreprodukcijsko razdoblje.

Predreprodukcijsko razdoblje obuhvaća vrijeme od rođenja do spolne zrelosti. U tom se periodu izlučuju hormoni koji su odgovorni za pravilnu produkciju spolnih (gonadalnih) hormona neophodnih za rast i razvoj spolnih organa; tijekom ovog razdoblja pod utjecajem spolnih hormona očituju se tipične sekundarne spolne osobine. Reprodukcijsko razdoblje počinje uspostavljanjem spolnog ciklusa i generativnom aktivnošću jajnika u ženke, a u mužjaka aktivnošću testisa (Đuričić, 2017.).

Spolna zrelost ili pubertet predstavlja početak spolne aktivnosti u mladih životinja. Tijekom tog razdoblja dolazi do pojačanog rasta i razvoja spolnih organa te početka njihove funkcije. U tom periodu se mužjak i/ ili ženka smatraju sposobnim za rasplodnju. U ženki dolazi do prve ovulacije, a u mužjaka se $u$ ejakulatu nalaze spermiji (Đuričić, 2017.).

Razina testosterona u mužjaka alpake je po rođenju niska (60 - 90 $\mathrm{pg} / \mathrm{mL}$ ), a između penisa i prepucija 
postoje priraslice (Bravo, 1995., Bravo i sur., 2002.). Spolna zrelost u mužjaka alpake započinje nakon 12. mjeseca starosti, kada u sjemenim kanalićima započinje spermatogeneza (Galloway, 2000.). S oko 20 mjeseci starosti testisi se povećavaju, a razina testosterona naraste na više od 1000 pg/mL (Bravo i sur., 2002.). Porast testosterona utječe i na raskidanje priraslica između testisa i prepucija s vrha penisa u dobi od 12 - 15 mjeseci. Pola glavića penisa je slobodno s godinu i pol, a cijeli penis je slobodan od priraslica oko 2 godine starosti (Sumar, 1983., Fernandez-Baca, 1993., Smith i sur., 1994., Fowler i Bravo, 1998.). Za razliku od južnoameričkih kamelida, mužjaci jednogrbih deva spolnu zrelost postižu nešto kasnije u dobi od 3 - 4 godine (Bravo i Johnson, 1994., Bravo, 1995.). Pubertet se u ženki kamelida očituje povećanom proizvodnjom estrogena i progesterona, spolnih hormona jajnika. Deve Starog svijeta spolno su zrele u dobi od 2 godine, ali u praksi se pripuštaju tek s 3 - 4 godine starosti (Abdel Rahim, 1997.). Alpake dosegnu spolnu zrelost u dobi od 12 - 14 mjeseci, a mogu se pripustiti nakon 18. mjeseca (Bravo, 1994., Đuričić i sur., 2018.). U kamelida do ovulacije ne dolazi spontano, već imaju tzv. induciranu ovulaciju koja je izazvana kopulacijom (Musa i Abusineina, 1978., Adams i sur., 1990., Skidmore i sur., 1995.). Zbog ovisnosti ovulacije o kopulaciji, početak spolne zrelosti kamelida ovisi o starosti ženke pri prvom parenju.

Poznato je da ranijem početku puberteta kako u ženki tako i u mužjaka, pogoduju zadovoljavajući hranidbeni status i uvjeti držanja (Đuričić, 2018.). Ženke kamelida nemaju redovite spolne cikluse kao ostale domaće životinje. Ipak, unatoč tome što se životinja nije parila aktivnost jajnika postoji. Ponavljajući valovi folikulostimulirajućeg hormona (FSH) dovode do izmjenjivanja rasta i razvoja folikula. Rast folikula možemo podijeliti u tri faze: preantralnu (primordijalni, primarni i sekundarni folikuli), fazu prijelaza iz preantralne $u$ rani antralni stadij i fazu rasta antralnih folikula (odabir, dominacija i regresija folikula). Tijekom folikularnog vala nekoliko folikula (sekundarnih) regrutira tako da se pojavi određen broj antralnih folikula koji narastu do promjera od 4 - $5 \mathrm{~mm}$. Jedan od tih folikula postaje dominantan, ostali zbog visoke razine estradiola $\mathrm{u}$ plazmi koju izlučuje dominatni folikul atreziraju, a negativno djeluje i na izlučivanje FSH iz hipofize. Nakon kopulacije dolazi do inducirane ovulacije i posljedičnog povećanja LH vala. Povećanje LH vala dovodi do pucanja dominantnog folikula i oslobađanja jajne stanice $u$ jajovod. U slučaju da ne dođe do kopulacije, dominantni folikul sazrije i dolazi do njegove regresije. Prije konačne regresije dominantnog folikula, počinje rast novih folikula tijekom nekoliko dana, tj. dolazi do tzv. preklapajućih folikularnih valova. Jedan folikularni val traje u prosjeku 20 - 25 dana. Stadij rasta folikula traje oko 9 dana, stadij mirovanja oko 5 dana, a regresija 8 dana. Vrijeme proteklo između dva uzastopna vala iznosi 16 - 20 dana (Skidmore, 2005.). Dominantni folikul dosegne najveći promjer $(12 \mathrm{~mm}) 12$ dana nakon početka faze rasta u ljame, odnosno 8 dana $\mathrm{u}$ alpake $(9 \mathrm{~mm})$. Stopa rasta folikula je $0,5-1 \mathrm{~mm} /$ dan. Tijekom folikularne faze bazalna koncentracija LH je 2,7 $7 \pm 1,2$ $\mathrm{ng} / \mathrm{mL}$, a koncentracija progesterona $\mathrm{u}$ krvnoj plazmi je niska $(0,36 \pm 0,28 \mathrm{ng} / \mathrm{mL})$ (Skidmore, 2005.). Razina progesterona poveća se na $1,73 \pm 0,74 \mathrm{ng} / \mathrm{mL} 3$ dana i na 2,4 $\pm 0,86 \mathrm{ng} / \mathrm{mL} 7$ dana nakon ovulacije. Koncentracija estradiola je $26 \pm 9,0$ pg/mL tijekom folikularne faze i $30,8 \pm 5,1 \mathrm{pg} / \mathrm{mL}$ kad je folikul maksimalne veličine. Promjer dominantnog folikula i razina estradiola je proporcionalna (Skidmore i sur., 1996., Đuričić, 2018.).

Akt kopulacije, feromoni mužjaka, zvuci koje proizvodi mužjak tijekom parenja i položene prednje noge oko ženkina tijela su podražaji koji se 
obrađuju u mozgu i dovode do stimulacije hipotalamusa (hypothalamus) koji počinje izlučivati gonadotropni releasing hormon $(\mathrm{GnRH})$. GnRH potiče hipofizu na izlučivanje luteinizirajućeg hormona (Bogle i sur., 2012.). Porast razine LH dovodi do pucanja zrelog folikula na jajniku i oslobađanja jajne stanice što nazivamo ovulacijom. Vrhunac izlučivanja LH nastupa dva sata nakon parenja, a vraća se na početnu razinu 6 sati poslije parenja. Tri dana nakon ovulacije završen je proces luteinizacije i nastaje žuto tijelo koje izlučuje hormon progesteron. U slučaju neuspjele koncepcije do regresije CL dolazi 9-11 dana nakon parenja (Skidmore i sur., 1998.).

\section{Rasplodna zrelost}

Razdoblje kada su mužjak i/ili ženka spremni za rasplod nazivamo rasplodnom zrelošću. Mužjake alpake smatramo rasplodno zrelima kada $u$ potpunosti nestanu priraslice izmedu penisa i prepucija. U mužjaka jednogrbih deva rasplodna zrelost nastupa $\mathrm{u}$ dobi od 5 godina, a u mužjaka alpaka s 3 godine. Mlade ženke ulaze u rasplod kad dosegnu najmanje $70 \%$ tjelesne težine odrasle jedinke. U jednogrbih deva praksa je pripuštati ženke u dobi od 3-4 godine (Musa i Abusineina, 1978.), dok ljame i alpake nešto ranije postižu rasplodnu zrelost, već u dobi od 2 godine. Treba naglasiti da prerano stupanje $u$ spolni odnos i gravidnost prije rasplodne zrelosti zbog mogućnosti teških porođaja nisu poželjni (Đuričić, 2017.).

\section{Sezonost rasplodnje}

Sezonost spolne aktivnosti je obilježje rasplodnje divljih životinja u cilju održanja vrste, jer je važno dobiti potomstvo u doba kad će majka i mladunče imati najviše hrane i najveću mogućnost da prežive. Kamelidi u svojim postojbina- ma su sezonski poliestrične životinje, ali ako hrane ima u izobilju i uvjeti držanja su zadovoljavajući, ženke se mogu tjerati tijekom cijele godine (Sghiri i Driancourt, 1999.). Deve svrstavamo u životinje čija se rasplodnja odvija tijekom razdoblja skraćenja dana (engl. short-day breeders). Neki autori smatraju da u kamelida niža temperatura zraka i količina padalina imaju mnogo važniju ulogu na rasplodnju nego fotoperiod. Jednogrbe deve su u prirodnim uvjetima držanja najplodnije od studenog do ožujka, dok za ljame i alpake na visoravnima Anda rasplodna sezona počinje za vrijeme kišnih mjeseci od studenog do travnja. U SAD-u se ljame i alpake rasplođuju cijele godine. U Indiji se deve pare od kraja rujna do ožujka (Vyas i sur., 2015.), u Sahari od listopada do svibnja (Abdussamad i sur., 2011.), a na Bliskom istoku od listopada do kraja travnja (Musa i Abusineina, 1978.).

Unatoč tome što je vrijeme sezone parenja deva promjenjivo, može se zaključiti da se ono podudara s razdobljem niske relativne vlažnosti zraka, niske temperature zraka i povećane količine oborina (Tibary i Anouassi, 1997., Sghiri i Driancourt, 1999., Marai i sur., 2009., Nagy i Juhasz, 2012., Đuričić, 2017., 2018.). Spermatogeneza se u deva odvija tijekom cijele godine. Spermiji se nalaze uz lumen sjemenih kanalića. Ovisno o pasmini i sezoni nailazimo na razlike $\mathrm{u}$ veličini testisa i promjeru sjemenih kanalića. Veličina testisa, sjemenih kanalića i intersticijskog tkiva su $u$ porastu tijekom sezone parenja. Testisi izvan sezone parenja u mužjaka deva teže 140 - $165 \mathrm{~g}$, a u sezoni više od 180 g. Izvan sezone dolazi do degeneracije testisa, tubuli su oskudni spermom i smanjuje im se promjer. U Peruu, gdje je praksa odvajanja mužjaka od ženki alpaka, razina testosterona raste s 3900 na 9000 pg/mL, dok je u SAD-u razina testosterona $\mathrm{u}$ alpaka niska, jer se tjeraju cijele godine (Delhon i Lawzewitsch, 1987., Hafez 1993., Fowler i Bravo, 1998.). 


\section{Spolni ciklus}

Spolni ciklus je razdoblje od početka jednog tjeranja (estrusa) do početka drugog tjeranja. U kamelida spolni ciklus traje 2 - 3 tjedna, a sam estrus 3 - 4 dana (Musa i Abusineina, 1978.). Tijekom rasplodne sezone primjećuje se stalan razvoj funkcionalnih folikularnih valova (Sghiri i Driancourt, 1999.). Estrus ili razdoblje spolnog žara predstavlja fazu u kojoj je ženka spremna za pripust ili umjetno osjemenjivanje (UO). Spremnost za parenjem ženka deve pokazuje zaskakivanjem drugih deva, mirnim stajanjem pokraj mužjaka, učestalim mokrenjem i brzom uzastopnom vrtnjom repa gore-dolje (Skidmore, 2005., Đuričić, 2017.). Mužjaci postaju agresivni, započinju borbe za prevlast i dominaciju u haremu. Karakteristično je za mužjake jednogrbih deva napuhivanje dule (produženja mekog nepca koje visi niz usta), grgljanje i pojačano slinjenje kako bi privukli ženke i pokazali prevlast. Karakterističan miris ženki u estrusu potiče tzv. flehmen reakciju (podizanje gornje usne). Mužjak širi stražnje noge, a rep podvlači prema penisu po kojem se pomokri te mokraću rastresa i repom utrljava na leđa. Iz zatiljnih žlijezda izlučuje tamnu tvar neugodnog mirisa (Oujad i Kamel, 2009., Đuričić, 2018.). Nakon uspostave hijerarhije u stadu, dominantni mužjak počinje slijediti ženku. Ženke pokazuju zainteresiranost za parenje tako što ubrzo nakon što ih mužjak počne slijediti legnu. Gravidne ženke, zbog prisutnosti CL koje izlučuje velike količine progesterona, pokazuju nezainteresiranost i bježe od mužjaka. Ponekad mužjak unatoč odbijanju ne odustaje, slijedi ženku i pokušava je zaskočiti stavljajući prednje noge na njezina leđa pritišćući je prema tlu. Nezainteresirane ženke pritom bježe, udaraju mužjaka nogama, pljuju i ispuštaju visoke tonove. Neke ženke popuste upornom mužjaku, legnu i dopuste kopulaciju, ali takva parenja $\mathrm{u}$ većini slučajeva ne završavaju gravidnošću. Faza udvaranja ne traje dugo, a pokušaj udvaranja duži od četiri minute često završava neuspješnim parenjem (England i sur., 1971., Fowler i Bravo, 1998.).

U južnoameričkih kamelida parenje se također odvija u sjedećem, sternalnom položaju pri čemu su prednje i stražnje noge ženke podvučene pod tijelo. Mužjak opkorači ženku, ramena ženke fiksira svojim laktovima, dok su mu metatarzusi naslonjeni na tlo uz ženku. Pri samom činu parenja ženka je submisivna i pasivna, dok mužjak stenje, podiže i spušta rep, širi nosnice i grglja. Nakon što ženka zauzme stav, mužjak liježe na nju i penisom prodire $\mathrm{u}$ rodnicu te pomoću hrskavičnog izdanka na glaviću penisa ulazi u grljak maternice. Iako sjeme polaže u oba maternična roga, a ovulacije se jednakomjerno izmjenjuju na oba jajnika, u 98 \% slučajeva ženka nosi plod u lijevom rogu. Životni vijek spermija nije poznat, a do ovulacije u deva dolazi 30-48 sati nakon parenja. Pretpostavlja se da je kapacitacija završena i akrosoma aktivirana nakon 18 sati kad su spermiji stigli do isthmusa. Grljak maternice je uslijed upalne reakcije izazvane sjemenom plazmom 24 sata nakon kopulacije hemoragičan, edematozan i hiperemičan (El-Wishy, 1988., Abdel Rahim, 1997.).

Stadij kopulacije alpaka traje prosječno 20 - 25 minuta. Na kopulaciju utječu pasmina, starost, godišnje doba, učestalost parenja i prisutnost drugih ženki (Brown, 2000.). Kopulacija traje duže $u$ jesen nego u proljeće, a mužjaci koji su u stadu s drugim mužjacima kopuliraju kraće (15 min) od onih držanih samostalno (20 min). Kopulacija s mladim ženkama traje kraće. Broj dnevnih parenja mužjaka ima znatan utjecaj na plodnost i postotak koncepcije. Dokazano je da je uspjeh koncepcije stalan ukoliko mužjak kopulira 3 - 4 puta na 
dan tijekom 4-5 dana. Ejakulat mužjaka kamelida je, ovisno o koncentraciji spermija mliječne do kremasto-bijele boje, viskozne konzistencije i gust. Sjeme se sastoji se od spermija i sjemene plazme (Žura Žaja i sur., 2019.), tj. u kamelida $11,5 \%$ spermija i $88,5 \%$ sjemene plazme. Stupanj kiselosti sjemena iznosi 7,2 - 7,8. Volumen ejakulata jednogrbe deve iznosi 4 - $6 \mathrm{~mL}$, a koncentracija spermija 312 $336 \times 10^{6} \mathrm{u} \mathrm{mL}$. U alpake koncentracija varira oko $150 \times 10^{6} \mathrm{u} \mathrm{mL}$, a volumen 1 - 2 mL. Zbog viskoznosti sjemena, sjeme je teško razrijediti i odrediti pokazatelje kakvoće. Spermiji postaju progresivno pokretljivi kad ejakulat postane tekući. Koncentraciju spermija je moguće odrediti nakon likvefakcije sjemena koja nastupa u prosjeku 23 sata nakon polučivanja (England i sur., 1971., Von Kubicek, 1974., Johnson, 1989., Knight i sur., 1992., Garnica i sur., 1993., Garnica i sur., 1995., Pollard i sur., 1995., Bravo i sur., 1997.a,b, Fowler, 2010., Đuričić, 2017.).

Tijekom rasplodne sezone mužjak može oploditi 20 - 50 ženki. Uspješnost parenja, između ostalog, ovisi i o metodi parenja. Kod haremskog parenja mužjak je cijelu godinu sa ženkama, ali je vrijeme porođaja neizvjesno. Stalna prisutnost mužjaka djeluje negativno na libido te postaje nezainteresiran. Bolja metoda parenja je parenje iz ruke kad se mužjak $\mathrm{i}$ ženka $\mathrm{u}$ estrusu stave $\mathrm{u}$ isti obor $\mathrm{i}$ nadgledaju. Nakon toga se odvajaju, a svaki drugi dan se puštaju zajedno u obor sve dok jedan ne odbije parenje. Ako parenje ne uspije, postupak se ponavlja za 2-3 tjedna. Ovom metodom možemo očekivati porođaj $u$ točno određeno vrijeme (Sumar, 1983., Fernandez-Baca, 1993., Đuričić, 2018.).

\section{Literatura}

1. ABDEL RAHIM, E. A. (1997): Studies on the age of puberty of male camels in Saudi Arabia. Vet. J. 154, 79-83.
2. ABDUSSAMAD, A. M., W. HOLTZ, M. GAULY, M. S. SULEIMAN and M. B. BELLO (2011): Reproduction and breeding in the dromedary camel: insights from pastoralists in some selected villages of the Nigeria-Niger corridor. Livst. Res. Rural Dev. 23:8.

3. ADAMS, G. P., J. SUMAR and O. J. GINTHER (1990): Effects of lactational and reproductive status on ovarian follicular waves in llamas (Lama glama). J. Reprod. Fertil. 90, 535-545.

4. ALI, H. A, K. A. MONIEM and M. D. TINGARI (1976): Some histochemical studies on the prostate, urethral and bulbourethral glands of the onehumped camel (Camelus dromedarius). Histochem. J. 8, 565-578.

5. BOGLE, O. A., M. H. RATTO and G. P. ADAMS (2012): Ovulation-inducing factor (OIF) induces LH secretion from pituitary cells. Anim. Reprod. Sci. 133, 117-122.

6. BRAVO, P. W. (1994): Reproductive endocrinology of llamas and alpacas. Vet. Clin. North Am. Food Anim. Pract. 10, 265-279.

7. BRAVO, P. W. and L. W. JOHNSON (1994): Reproductive physiology of the male camelid. In: Johnson, L. W. (ed.) Update on Llama Medicine. Veterinary Clinics of North America Food Animal Practice WB Saunders, Philadelphia 10, pp. 259-264.

8. BRAVO, P. W. (1995): Physiology of reproduction and fertility evaluation in the male alpaca. Proceedings of Post Graduate Foundation in Veterinary Science 257, pp. 61-66.

9. BRAVO, P. W., U. FLORES, J. GARNICA and C. ORDONEZ (1997a): Collection of semen and artificial insemination of alpacas. Theriogenology 47, 619-626.

10. BRAVO, P. W., D. FLORES and C. ORDONEZ (1997b): Effect of repeated collection on semen characteristics of alpacas. Biol. Reprod. 57, 520-524.

11. BRAVO, P. W., R. MOSCOSO, V. ALARCON and C. ORDONEZ (2002): Ejaculatory process and related semen characteristics. Arch. Androl. 48, 65-72.

12. BROWN, B. W. (2000): A review on reproduction in South American camelids. Anim. Reprod. Sci. 58, 169-195.

13. DELHON, G. A. and I. LAWZEWITSCH (1987): Reproduction in the male llama (Lama glama), a South American camelid. I Spermatogenesis and organisation of the intertubular space of the mature testis. Acta Anatom. 129, 59-66.

14. ĐURIČIĆ, D. (2017): Camels. Ed. D. Đuričić. Vlastita naklada autora. (In Croatian).

15. ĐURIČIĆ, D., H. VALPOTIĆ and M. SAMARDŽIJA (2018): Mating properties of male alpacas (Vicugna pacos, L.) Vet. stn. 49, 37-42. (In Croatian).

16. ĐURIČIĆ, D. (2018): Physiology and patology of lamas and alpacas. Ed. M. Samardžija. „A je to" art Podravina, Đurđevac. (In Croatian).

17. ENGLAND, B. G., W. C. FOOTE, A. G. CARDOZO, D. H. MATTHEWS and S. RIERA (1971): Oestrus and mating behaviour in the llama (Lama glama). Anim. Behav. 19, 722-726. 
18. EL-WISHY (1988): A review on reproduction in the male dromedary (Camelus dromedarius). Anim. Reprod. Sci. 17, 217-241.

19. FERNANDEZ-BACA, S. (1993): Manipulation of reproductive functions in male and female New World camelids. Anim. Reprod. Sci. 33, 307-323.

20. FOWLER, M. E. and P. W. BRAVO (1998): Reproduction. In: Fowler M. E., Medicine and surgery of South American camelids. 2nd edition. Iowa State University Press, pp. 381-429.

21. FOWLER, M. E. (2010): "Medicine and Surgery of Camelids", Ames, Iowa: Wiley-Blackwell. Chapter 1 General Biology and Evolution addresses the fact that camelids (including camels and llamas) are not ruminants, pseudo-ruminants, or modified ruminants.

22. GALLOWAY, D. B. (2000): The development of the testicles in alpacas in Australia. Proceedings of the Australian Alpaca Industry Conference, Canberra, pp. 21-23.

23. GARNICA, J., R. ACHATA and P. W. BRAVO (1993): Physical and biochemical characteristics of alpaca semen. Anim. Reprod. Sci. 32, 85-90.

24. GARNICA, J. E. FLORES and P. W. BRAVO (1995): Citric acid and fructose concentrations in seminal plasma of alpaca. Small Rumin. Res. 18, 95-98.

25. GRAY, J. E. (1821): “On the natural arrangement of Vertebrose Animals." London Medical Repository 15, pp. 296-310.

26. HAFEZ, E. S. E. (1993): Artificial insemination. In: Hafez, E. S. E. (ed.). Reproduction in Farm Animals. $6^{\text {th }}$ ed. Lea \& Febiger, Baltimore, pp. 424-439.

27. JOHNSON, L. W. (1989): Llama reproduction. In: Johnson L. W. (ed.) Llama medicine. Veterinary Clinics of North America Food Animal Practice WB Saunders, Philadelphia, 5, 159-182.

28. KNIGHT, T. W., A. DEATH, T. WYETH and F. HILL (1992): Effects of GnRH and of single versus multiple mating on the conception rate in alpacas. Proceedings of the New Zealand Society of Animal Production, 52, pp. 311-312.

29. MARAI, I., A. ZEIDAN, A. ABDEL-SAMEE, A. ABIZAID and A. FADIEL (2009): Camel's reproductive and physiological performance trails as affect by environmental conditions. Tropical and Subtropical Agroecosystems 10, 129-149.

30. MUSA, B. E. and M. E. ABUSINEINA (1978): The oestrous cycle of the camel (Camelus dromedarius). Vet. Rec. 102, 556-557.

31. NAGY, P. and J. JUHASZ (2012): Fertility after ovarian follicular wave synchronization and fixedtime natural mating compared to random natural mating in dromedary camels (Camelus dromedarius). Anim. Reprod. Sci. 132, 223-230.

32. OUJAD, S. and B. KAMEL (2009): Physiological particularities of dromedary (Camelus dromedarius) and experimental implications. Scand J. Lab. Anim. Sci. 36, 19-29.

33. PERK, K. (1962): Seasonal changes in the glandula bulbo-urethralis of the camel. Bull Res. Counc. Isr. Sect. E Exp. Med. 10, 37-44.
34. PÉREZ, W., H. E. KÖNIG, H. JERBI and M. CLAUSS (2016): Macroanatomical aspects of the gastrointestinal tract of the alpaca (Vicugna pacos Linnaeus, 1758) and dromedary (Camelus dromedarius Linnaeus, 1758). Vertebr. Zool. 66, 419-425.

35. POLLARD, J. C., R. P. LITTLEJOHN and G. H. MOORE (1995): Sesonal and other factors affecting the sexual behaviour of alpacas. Anim. Reprod. Sci. 37, 349-356

36. SGHIRI, A. and M. A. DRIANCOURT (1999): Seasonal effects on fertility and ovarian follicular growth and maturation in camels (Camelus dromedarius). Anim. Reprod. Sci. 55, 223-237.

37. SKIDMORE, J. (2005): Reproduction in dromedary camels: an update. Anim. Reprod. 2, 161-171.

38. SKIDMORE, J. A., M. BILLAH and W. R. ALLEN (1995): The ovarian follicular wave pattern in the mated and non-mated dromedary camel (Camelus dromedarius). J. Reprod. Fertil. 49, 545-548.

39. SKIDMORE, J. A., M. BILLAH and W. R. ALLEN (1996): The ovarian follicular wave pattern and induction of ovulation in the mated and nonmated one - humped camel (Camelus dromedarius). J. Reprod. Fertil. 106, 185-192.

40. SKIDMORE, J. A., G. R. STARBUCK, G. E. LAMMING and W. R. ALLEN (1998): Control of luteolysis in the one-humped camel (Camelus dromedarius). Reprod. Fertil. 114, 201-209.

41. SMITH, B. B. (1999): Overview of reproduction in the male llama and alpaca. Proceedings of the Society for Theriogenology, pp. 191-196.

42. SMITH, C. L., A. T. PETER and D. G. PUGH (1994): Reproduction in llamas and alpacas: A review. Theriogenology 41, 573-592.

43. SUMAR, J. (1983): Studies on reproductive pathology in alpacas. Masters Thesis. Swedish University of Agricultural Sciences, Uppsala and Universidad Nacional Mayor de San Marcos, pp. 9-103.

44. TAHA, A. A., E. M. ABDEL-MAGIED, M. A ABDALLA and A. B. ABDALLA (1994): The poll glands of the dromedary (Camelus dromedarius): ultrastructural characteristics. Anat. Histol. Embryol. 23, 269-274.

45. TIBARY, A. and A. ANOUASSI (1997): Reproductive physiology in the Female Camelidae In: A. Tibary, (ed.). Theriogenology in Camelidae: anatomy, physiology, BSE, pathology and artificial breeding. Actes Editions: Institut Agronomique et Vétérinaire Hassan II, pp. 317-368.

46. TINGARI, M. D. and M. A. GEORGE (1984): Studies on the poll glands of the one-humped camel in relation to reproductive activity. II. Ultrastructural observations. J. Anat. 139, 463-474.

47. VON KUBICEK, J. (1974): Samentnahme beim Alpaca durch eine Harnrohrenfistel. Z. Tierzuecht. Zuechtungsbiol. 90, 335-351.

48. VAUGHAN, J. L. and J. TIBARY (2006): Reproduction in female south american camelids: a review and clinical observations. Small Rumin. Res. 61, 259-281. 
49. VYAS, S., N. SHARMA, F. D. SHEIKH, S. SINGH, D. S. SENA and U. K. BISSA (2015): Reproductive status of Camelus bactrianus during early breeding season in India. Asian Pacific J. Reprod. 4,61-64.

50. WHEELER, J. C. (2012): South American camelids past, present and future. J. Camel Sci. 5, 1-24.
51. ŽURA ŽAJA, I., I. ŠVUB, S. MILINKOVIĆ-TUR, S. VINCE, H. VALPOTIĆ, D. ĐURIČIĆ, S. ČIPČIĆ and M. SAMARDŽIJA (2019): Biochemical parameters of seminal plasma in domestic animals and humans. Vet. stn. 50, 223-237. (In Croatian).

\section{Physiology of reproduction in camelids - Anatomy of reproductive organs and sexual maturity Part $\mathrm{I}$.}

Dražen ĐURIČIĆ, DVM, PhD, Assistant Professor, Veternary Practice Đurđevac, Croatia; Iva KILVAIN, DVM, Croatian Veterinary Institute - Regional Laboratories Rijeka, Croatia; Marko SAMARDŽIJA, DVM, PhD, Full Professor, Faculty of Veterinary Medicine University of Zagreb, Croatia

In natural conditions, the efficiency of breeding in camelids is relatively low. The reproductive physiology of camelids differs to that of other domestic animals. Generation intervals are relatively long as males are slow to sexually mature and females exhibit an extended gestation period in comparison to domestic ruminants. Camelids are seasonally polyoestrous animals whose seasonal reproduction is influenced by various factors. During the season, there is a steady development of functional follicular waves. Females are induced ovulators, where ovulation is induced by copulation. Dromedary camels are considered to be sexually mature at the age of 2 years but are capable of mating at 3 to 4 years, and males at $4-5$ years. Alpacas are sexually mature within $12-14$ months or capable of mating within 18 months, and males after 2 years. The sexual cycle lasts from 2 to 3 weeks and oestrus lasts from 3 - 4 days. During oestrus, the female is ready for mating/artificial insemination, and experiences changes in behaviour and characteristic changes to the reproductive organs. Mating is in sternal recumbency. The camelid ejaculate consists of low volume, high viscosity semen containing a low sperm concentration.

Keywords: camelids; puberty; sexual maturity; sexual cycle 